\title{
Extending large-scale forest inventories to assess urban forests
}

\author{
Piermaria Corona - Mariagrazia Agrimi - Federica Baffetta - Anna Barbati · \\ Maria Vincenza Chiriacò • Lorenzo Fattorini · Enrico Pompei • \\ Riccardo Valentini · Walter Mattioli
}

Received: 27 December 2010 / Accepted: 5 April 2011 / Published online: 5 May 2011

(C) Springer Science+Business Media B.V. 2011

\begin{abstract}
Urban areas are continuously expanding today, extending their influence on an increasingly large proportion of woods and trees located in or nearby urban and urbanizing areas, the socalled urban forests. Although these forests have the potential for significantly improving the quality the urban environment and the well-being of the urban population, data to quantify the extent and characteristics of urban forests are still lacking or fragmentary on a large scale. In this regard, an expansion of the domain of multipurpose forest inventories like National Forest Inventories (NFIs) towards urban forests would be required.
\end{abstract}

To this end, it would be convenient to exploit the same sampling scheme applied in NFIs to assess the basic features of urban forests. This paper considers approximately unbiased estimators of abundance and coverage of urban forests, together with estimators of the corresponding variances, which can be achieved from the first phase of most largescale forest inventories. A simulation study is carried out in order to check the performance of the considered estimators under various situations involving the spatial distribution of the urban forests over the study area. An application is worked out on the data from the Italian NFI.
P. Corona · M. Agrimi · A. Barbati $(\varangle)$.

M. V. Chiriacò · R. Valentini · W. Mattioli

Dipartimento di Scienze dell'Ambiente Forestale e delle sue Risorse (DISAFRI), Università della

Tuscia, via San Camillo de Lellis, s.n.c.

01100 Viterbo, Italy

e-mail: barbati.sisfor@unitus.it

P. Corona

e-mail: piermaria.corona@unitus.it

M. Agrimi

e-mail: agrimi@unitus.it

M. V. Chiriacò

e-mail: chiriaco@unitus.it

R. Valentini

e-mail: rik@unitus.it

\author{
W. Mattioli \\ e-mail: walter.mattioli@unitus.it \\ F. Baffetta $\cdot$ L. Fattorini \\ Dipartimento di Economia Politica e Statistica, \\ Università di Siena, P.za S. Francesco 8, \\ 53100 Siena, Italy \\ F. Baffetta \\ e-mail: baffetta@unisi.it \\ L. Fattorini \\ e-mail: fattorini@unisi.it \\ E. Pompei \\ Corpo Forestale dello Stato, Inventario Nazionale \\ delle Foreste e dei Serbatoi forestali di Carbonio \\ (CFS-INFC), via Carducci 5, 00187 Rome, Italy \\ e-mail: e.pompei@corpoforestale.it
}

